\title{
An efficient 4-step block method for solution ff first order initial value problems via shifted chebyshev polynomial
}

\author{
${ }^{* 1}$ Isah I. O., ${ }^{2}$ Salawu, A. S., ${ }^{3}$ Olayemi, K. S. and ${ }^{4}$ Enesi. L. O. \\ 1,2,3,4 Department of Mathematical Sciences, Kogi State University, Anyigba, Nigeria. \\ *Corresponding author: isahibrahim35@yahoo.com (+2348067094184)
}

\begin{abstract}
In this paper, we develop a four-step block method for solution_of first order initial value problems of ordinary differential equations. The collocation and interpolation approach is adopted to obtain a continuous scheme for the derived method via Shifted Chebyshev Polynomials, truncated after sufficient terms. The properties of the proposed scheme such as order, zero-stability, consistency and convergence are also investigated. The derived scheme is implemented to obtain numerical solutions of some test problems, the result shows that the new scheme competes favorably with exact solution and some existing methods.
\end{abstract}

Keywords: Interpolation, Collocation, Block method, Zero-stability, Convergence

\section{Introduction}

It is a general knowledge that differential equations model quite a lot of physical problems that occur in many fields of Sciences, Mathematics and Engineering; common among such differential equations are ordinary differential equations. Thus, the solutions to these differential equations and consequently the physical problems that they represent, have been a subject of interest to Mathematicians, particularly Numerical Analysts. A wide range of numerical schemes for solving initial value problems of first order ordinary differential equation using different approaches have been developed and are continuously being sort, with extension to higher order ordinary differential equations. Listing just a few of such research would include Lambert (1991), Lambert (1973), Ayinde and Ibijola (2015), Taiwo (2005), Ogunrinde et al (2012), Fadugba and Idowu (2019), Fadugba and Falodun (2017), Fadugba and Okunlola
(2017), Fadugba et al (2020), Aksah et al (2019), Sunday et al (2013), Suleiman et al (2013), Adeyeye and Kayode (2013), Odekunle et al (2012), Awoyemi (2014), Fatunla (1991), Yahaya (2007), Muhammed and Yahaya (2010), Adeniyi et al (2006), Aboiyar et al (2015), Olanegan et al (2016), Adeniyi and Alabi (2006), Onumanyi et al (1994) among other numerous numerical integrators for the solution of initial value problems of various orders. Many of the above mentioned methods employed interpolation and collocation approach in deriving schemes of varying accuracy for first order initial value problems. Hence, the evolution of ordinary differential equation as well as its properties and solvability has been and is still being extensively researched. The need to employ suitable polynomials which approximates a function accurately and uniformly on some interval $[a, b]$ is unceasing, hence the consideration of minimax approximants. Although 
Isah I. O., Salawu, A. S., Olayemi, K. S. and Enesi. L. O.: An Efficient 4-Step Block Method for Solution ff First Order Initial Value Problems via Shifted Chebyshev Polynomial

minimax polynomials exist and are unique when a function is continuous, they are not easy to compute in general. Therefore, a more effective approach is to consider nearminimax polynomials such as Chebyshev polynomials. However, Shifted Chebyshev polynomials are more suitable when the range of the independent variable is $[0,1]$ instead of $[-1,1]$.

The general definition of the Shifted Chebyshev polynomials is given as

$$
\begin{aligned}
& T_{n}^{*}(x)=T_{n}(2 x-1), \quad 0 \leq x \leq \\
& \quad 1
\end{aligned}
$$

In what follows, we shall develop a class of a four step linear multistep method using the Shifted Chebyshev polynomial as basis function and collocation and interpolation approach for the derivation of the method. The rest of this paper is divided into the following sections: section 2 gives the derivation of the method, sections 3 comprises of the analysis of the properties of the derived scheme to include order, error constants, zero-stability and convergence of the method, implementation of the method on some test problems is done in section 4 while section 5 is discussion and conclusion.

\section{Method derivation}

Consider the general form of a first order initial value problem:

$y^{\prime}=f(x, y(x)) y(a)=y_{0}, a \leq x \leq b$,

$a$ and $b$ being finite.
We assume that (2) has a solution, $y(x)$ of the form:

$$
y(x)=\sum_{i=0}^{s+m-1} T_{j}^{*} a_{i}\left(x-x_{n}\right)
$$

(3) is evaluated at $x_{n}$ and $x_{n+4}$, which are chosen as interpolation points to give:

$$
y\left(x_{n}\right)=a_{0}-a_{1}+a_{2}-a_{3}+a_{4}-a_{5}
$$

$$
\begin{aligned}
& y\left(x_{n+4}\right)=a_{0}+a_{1}(8 h-1)+ \\
& a_{2}\left(128 h^{2}-32 h+1\right)+a_{3}\left(2048 h^{3}-\right. \\
& \left.768 h^{2}+72 h-1\right)+a_{4}\left(32768 h^{4}-\right. \\
& \left.16384 h^{3}+2560 h^{2}-128 h+1\right)+ \\
& a_{5}\left(524288 h^{5}-327680 h^{4}+71680 h^{3}-\right. \\
& \left.6400 h^{2}+200 h-1\right)
\end{aligned}
$$

Also, the first derivative of (3) is obtained as:

$$
\begin{aligned}
& y^{\prime}(x)=f(x, y(x))=\sum_{i=1}^{s+m-1} T_{j}^{*} a_{i}(x- \\
& \left.x_{n}\right)
\end{aligned}
$$

(6) is then evaluated at $x_{n}, x_{n+1}, x_{n+2}$ and $x_{n+3}$, considered as collocation points to obtain:

$f\left(x_{n}\right)=2 a_{1}-8 a_{2}+18 a_{3}-32 a_{4}+50 a_{5}$

$$
\begin{aligned}
& f\left(x_{n+1}\right)=2 a_{1}+a_{2}(16 h-8)+ \\
& a_{3}\left(96 h^{2}-96 h+18\right)+a_{4}\left(512 h^{3}-\right. \\
& \left.768 h^{2}+320 h-32\right)+a_{5}\left(2560 h^{4}-\right. \\
& \left.5120 h^{3}+3360 h^{2}-800 h+50\right)
\end{aligned}
$$


Isah I. O., Salawu, A. S., Olayemi, K. S. and Enesi. L. O.: An Efficient 4-Step Block Method for Solution ff First Order Initial Value Problems via Shifted Chebyshev Polynomial

$$
\begin{aligned}
& f\left(x_{n+2}\right)=2 a_{1}+a_{2}(32 h-8)+ \\
& a_{3}\left(384 h^{2}-192 h+18\right)+a_{4}\left(4096 h^{3}-\right. \\
& \left.3072 h^{2}+640 h-32\right)+a_{5}\left(40960 h^{4}-\right. \\
& \left.40960 h^{3}+13440 h^{2}-1600 h+50\right)
\end{aligned}
$$

$$
\begin{aligned}
& f\left(x_{n+3}\right)=2 a_{1}+a_{2}(48 h-8)+ \\
& a_{3}\left(864 h^{2}-288 h+18\right)+a_{4}\left(13824 h^{3}-\right. \\
& \left.6912 h^{2}+960 h-32\right)+a_{5}\left(207360 h^{4}-\right. \\
& \left.138240 h^{3}+30240 h^{2}-2400 h+50\right)
\end{aligned}
$$

(4) , (5), (7), (8), (9) and (10) form a system of six equations in six unknowns $\left(a_{0}, a_{1}, a_{2}, a_{3}, a_{4}\right.$ and $\left.a_{5}\right)$ which result from the interpolation and collocation of the basis function (3). This system of equations is then solved to obtain the values for the unknown coefficients.

We recall that:

$$
\left.\begin{array}{c}
x_{n}=x_{0}+n h \\
x_{n+j}=x_{n}+j h \\
y\left(x_{n}\right)=y_{n} \\
y\left(x_{n+j}\right)=y_{n+j} \\
f\left(x_{n}, y\left(x_{n}\right)\right)=f_{n} \\
f\left(x_{n+j}, y\left(x_{n+j}\right)\right)=f_{n+j}
\end{array}\right\}
$$

Combining the solutions obtained in solving the system of equations in (4), (5), (7), (8), (9) and (10) with (11) and substituting back into (3), the continuous form of the proposed 4-step method is obtained as:

$$
\begin{aligned}
& \qquad y(x)=\sum_{j=0}^{j=4} a_{j}(x) y_{n+j}-h \\
& \sum_{j=0}^{j=4} \beta_{j}(x) f_{n+j}
\end{aligned}
$$

where $a_{j}$ and $\beta_{j}$ as obtained are:

$$
\left.\begin{array}{c}
a_{0}(x)=1+\frac{45\left(x-x_{n}\right)^{2}}{112 h^{2}}-\frac{55\left(x-x_{n}\right)^{3}}{112 h^{3}}+\frac{45\left(x-x_{n}\right)^{4}}{224 h^{4}}-\frac{3\left(x-x_{n}\right)^{5}}{112 h^{5}} \\
a_{4}(x)=\frac{45\left(x-x_{n}\right)^{2}}{112 h^{2}}+\frac{55\left(x-x_{n}\right)^{3}}{112 h^{3}}-\frac{45\left(x-x_{n}\right)^{4}}{224 h^{4}}+\frac{3\left(x-x_{n}\right)^{5}}{112 h^{5}} \\
\beta_{0}(x)=\left(x-x_{n}\right)-\frac{11\left(x-x_{n}\right)^{2}}{12 h}+\frac{\left(x-x_{n}\right)^{3}}{3 h^{2}}-\frac{\left(x-x_{n}\right)^{4}}{24 h^{3}} \\
\beta_{1}(x)=\frac{18\left(x-x_{n}\right)^{2}}{7 h}-\frac{15\left(x-x_{n}\right)^{3}}{7 h^{2}}+\frac{37\left(x-x_{n}\right)^{4}}{56 h^{3}}-\frac{\left(x-x_{n}\right)^{5}}{14 h^{4}} \\
\beta_{2}(x)=-\frac{9\left(x-x_{n}\right)^{2}}{7 h}+\frac{37\left(x-x_{n}\right)^{3}}{28 h^{2}}-\frac{11\left(x-x_{n}\right)^{4}}{28 h^{3}}+\frac{\left(x-x_{n}\right)^{5}}{28 h^{4}} \\
\beta_{3}(x)=\frac{26\left(x-x_{n}\right)^{2}}{21 h}-\frac{31\left(x-x_{n}\right)^{3}}{21 h^{2}}+\frac{97\left(x-x_{n}\right)^{4}}{168 h^{3}}-\frac{\left(x-x_{n}\right)^{5}}{14 h^{4}}
\end{array}\right\}
$$

We evaluate (12) at $x=x_{n}, x_{n+1}, x_{n+2}$ and $x_{n+3}$ while the derivative of (12) is evaluated at $x_{n+4}$ to yield the following four discrete schemes:

$$
\begin{gathered}
19 y_{n+4}+224 y_{n+1}-243 y_{n}=h\left(60 f_{n+3}-72 f_{n+2}+288 f_{n+1}+84 f_{n}\right. \\
3 y_{n+4}+84 y_{n+2}-87 y_{n}=h\left(8 f_{n+3}+24 f_{n+2}+120 f_{n+1}+28 f_{n}\right. \\
27 y_{n+4}+224 y_{n+3}-251 y_{n}=h\left(156 f_{n+3}+216 f_{n+2}+324 f_{n+1}+84 f_{n}\right. \\
45 y_{n+4}-45 y_{n}=h\left(14 f_{n+4}+64 f_{n+3}+24 f_{n+2}+64 f_{n+1}+14 f_{n}\right. \\
(14)
\end{gathered}
$$

The discrete schemes presented in (14) gives the proposed 4-step block method (4SBM) which directly integrates general first order initial value problems of ordinary differential equation. The derived method is self-starting and is thus potentially suitable and easy to implement as numerical solver for initial value problem of ordinary differential equations.

\subsection{Analysis of the Derived 4SBM \\ 3.1 Order of $4 S B M$}

According to Lambert (1973), the linear difference operator associated with (12) is defined by

$$
\begin{aligned}
& L[y(x) ; h]=\sum\left[\alpha_{j} y\left(x_{n}+j h\right)-\right. \\
& \left.h \beta_{j} f\left(x_{n}+j h\right)\right]
\end{aligned}
$$

where $y(x)$ is assumed to have continuous derivative of sufficiently high order. 
Isah I. O., Salawu, A. S., Olayemi, K. S. and Enesi. L. O.: An Efficient 4-Step Block Method for Solution ff First Order Initial Value Problems via Shifted Chebyshev Polynomial

The Taylor series expansion of (15) gives:

$$
\begin{aligned}
& L[y(x) ; h]=c_{0} y(x)+c_{1} h y^{\prime}(x)+ \\
& c_{2} h^{2} y^{\prime \prime}(x)+\cdots+c_{p} h^{p} y^{(p)}(x)+ \\
& c_{p+1} h^{p+1} y^{(p+1)}(x)+c_{p+2} h^{p+2} y^{(p+2)}(x)+
\end{aligned}
$$

where $c_{o}, c_{1}, \ldots, c_{p}$ are defined as:

$$
\left.\begin{array}{c}
c_{0}=\alpha_{0}+\cdots+\alpha_{k} \\
c_{1}=\sum_{j=0}^{k} j \alpha_{j} \\
\text { and } \\
c_{p}=\frac{1}{p !} \sum_{j=1}^{k} j^{p} \alpha_{j}-\frac{1}{(p-1) !} \sum_{j=1}^{k} j^{(p-1)} \beta_{j} \quad p \geq 2
\end{array}\right\}
$$

The derived method is said to be of order $p$ and error constant $c_{p+1}$ if

$$
c_{0}=c_{1}=\cdots=c_{p}=0, c_{p+1} \neq 0 .
$$

We now determine the $c_{p}{ }^{\prime} s$ for each of the four discrete schemes in the derived block method in (14) above as follows:

$$
\left.\begin{array}{c}
c_{0}=c_{1}=c_{2}=c_{3}=c_{4}=c_{5}=0, c_{6}=\frac{21}{5} \\
c_{0}=c_{1}=c_{2}=c_{3}=c_{4}=c_{5}=0, c_{6}=\frac{14}{15} \\
c_{0}=c_{1}=c_{2}=c_{3}=c_{4}=c_{5}=0, c_{6}=\frac{21}{5} \\
c_{0}=c_{1}=c_{2}=c_{3}=c_{4}=c_{5}=c_{6}=0, c_{7}=\frac{-8}{21}
\end{array}\right\}
$$

In light of (19), it can be deduced that the four discrete schemes in the derived $4 \mathrm{SBM}$ method are of non-uniform order $(5,5,5,6)^{T}$ with error constants: $c_{p+1}=\left[\frac{21}{5}, \frac{14}{15}, \frac{21}{5}, \frac{-8}{21}\right]$

\subsection{Consistency and Zero Stability of $4 S B M$}

According to Adeniyi et al (2006), a linear multistep method is said to be consistent if it is of order greater than or equal to 1 .

Since the derived method is of order greater than one, we conclude that the method is consistent.

Also, as stated in Henrici (1962), a linear multistep method is zero-stable for any well behaved initial value problem if

- all roots of the first characteristic polynomial, $\rho(r)$ lies within the unit circle, $|r| \leq 1$.

- any roots of $\rho(r)$ on the unit circle $(|r|=1)$ are simple.

In addition, (1) $=0, \rho^{\prime}(1)=\sigma(1)$. where $\sigma(r)$ is the second characteristic polynomial.

The first and second characteristic polynomials are defined respectively as:

$$
\left.\begin{array}{l}
\rho(r)=\sum_{j=0}^{k} \alpha_{j} r^{j} \\
\sigma(r)=\sum_{j=0}^{k} \beta_{j} r^{j}
\end{array}\right\}
$$

Obtaining the first characteristic polynomials of the discrete schemes in the derived 4SBM in (14) gives:

$$
\left.\begin{array}{c}
\rho_{1}(r)=19 r^{4}+224 r-243 \\
\rho_{2}(r)=3 r^{4}+84 r^{2}-87 \\
\rho_{3}(r)=27 r^{4}+224 r^{3}-251 \\
\rho_{4}(r)=45 r^{4}-45
\end{array}\right\}
$$

Also, the second characteristic polynomials are obtained as: 
Isah I. O., Salawu, A. S., Olayemi, K. S. and Enesi. L. O.: An Efficient 4-Step Block Method for Solution ff First Order Initial Value Problems via Shifted Chebyshev Polynomial

$$
\left.\begin{array}{c}
\sigma_{1}(r)=60 r^{3}-72 r^{2}+288 r+84 \\
\sigma_{2}(r)=8 r^{3}+24 r^{2}+120 r+28 \\
\sigma_{3}(r)=156 r^{3}+216 r^{2}+324 r+84 \\
\sigma_{4}(r)=14 r^{4}+64 r^{3}+24 r^{2}+64 r+14
\end{array}\right\}
$$

We note that $\rho_{4}(r)$ in (22) and $\sigma_{4}(r)$ in (23) represents the first and second characteristic polynomials of the main scheme respectively which we denote as $\rho(r)$ and $\sigma(r)$.

Furthermore, the roots of the first characteristic polynomial are given as:

$\rho(r)=[1,-1, i,-i]$

i.e. the roots of the $\rho(r)$ lies within the unit circle and all roots with modulus 1 are simple.

It is equally observed that $\rho(1)=0$ and $\rho^{\prime}(1)=\sigma(1)$ which also holds for all the other three schemes in the derived method.

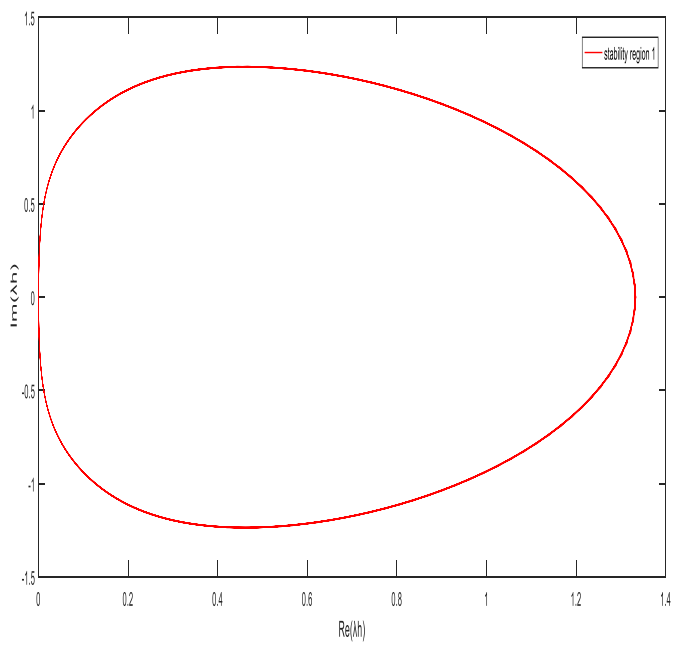

Fig 1: Stability Region for Scheme 1
Consequently, the 4SBM method is considered to be zero stable.

\subsection{Convergence of 4SBM}

Following Lambert (1991), the necessary and sufficient conditions for convergence are consistency and stability. The derived method was shown to be consistent and zero-stable, hence it is convergent.

\subsection{Region of Stability}

Consider the test problem:

$$
y^{\prime}=-\lambda y, \quad y(0)=1
$$

where $\lambda$ is a complex constant.

We apply (25) to each of the discrete schemes in (14) and plot the respective regions of stability for the schemes using MATLAB R2016a software as given in the figures below:

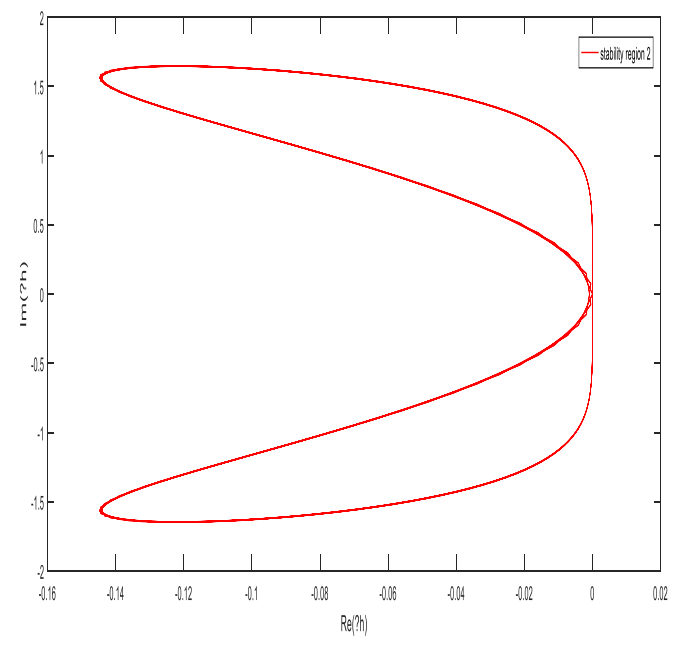

Fig 2: Stability Region for Scheme 2 
Isah I. O., Salawu, A. S., Olayemi, K. S. and Enesi. L. O.: An Efficient 4-Step Block Method for Solution ff First Order Initial Value Problems via Shifted Chebyshev Polynomial

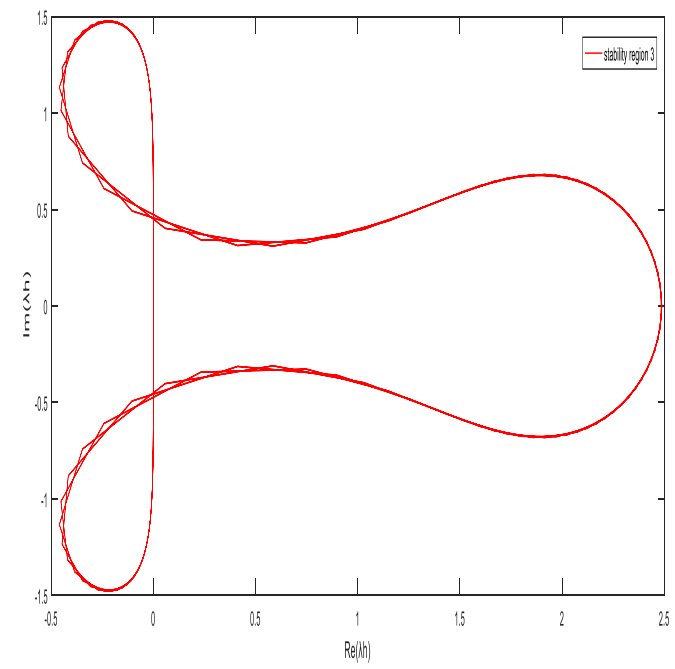

Fig 3: Fig 1: Stability Region for Scheme 3

\section{Results}

\subsection{Numerical results}

In this section, we examine the performance of 4SBM in terms of accuracy and stability when compared with exact solution (ES). Also, a comparative study of 4SBM and some existing methods in the form of Fadugba et al (2020) and Aksah et al (2019) is presented. All numerical computations were carried out with the aid of MAPLE 17, 64bits software.

The following notations are used:

SCNM : Second Order

Numerical Method... by Fadugba et al (2020)

SDIBBDF : Singly diagonally implicit BBDF method by Aksah et al (2019)

Problem 1

$$
\frac{d y}{d x}-x \sin x=0, \quad y(0)=1, \quad x \in[0,1]
$$

The exact solution to problem 1 is given by: $y(x)=1+\sin x-x \cos x$

Source: Fadugba et al (2020)

\section{Problem 2}

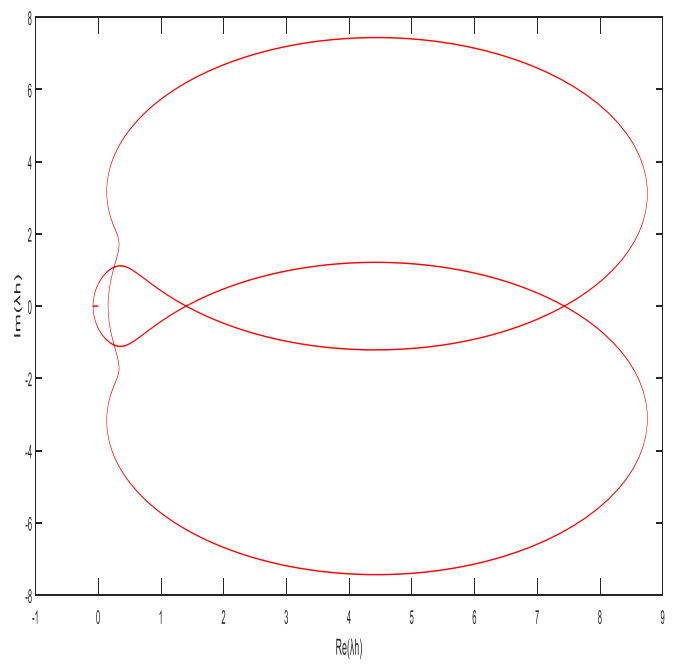

Fig 4: Fig 1: Stability Region for Scheme 4

$$
\begin{gathered}
\frac{d y}{d x}-1-(y-x)^{2}=0, \quad y(0)=\frac{1}{2}, \quad x \\
\in[0,1]
\end{gathered}
$$

Exact solution: $y(x)=\frac{(x+1)^{2}}{x+2}$

Source: Fadugba et al (2020)

Problem 3

We consider the Riccati equation coupled with initial condition as given below:

$$
\begin{gathered}
\frac{d y}{d x}+4-4 y+y^{2}=0, \quad y(0)=1, \quad x \\
\in\left[0, \frac{2}{5}\right]
\end{gathered}
$$

with exact solution: $y(x)=\frac{2 x-1}{x-1}$ having a pole at $x=1$.

Source: Fadugba et al (2020)

Problem 4

Consider the stiff initial value problem:

$$
\begin{gathered}
y^{\prime}=-20 y+20 \sin x+\cos x, \quad y(0) \\
=1, \quad x \in[0,1]
\end{gathered}
$$

Exact Solution: $y(x)=\sin x+e^{-20 x}$, Eigenvalue: $\lambda=-20$

Source: Aksah et al (2019) 
Isah I. O., Salawu, A. S., Olayemi, K. S. and Enesi. L. O.: An Efficient 4-Step Block Method for Solution ff First Order Initial Value Problems via Shifted Chebyshev Polynomial

Each of problems 1 to 4 is solved with the derived 4SBM in their respective intervals with $h=0.05$ and the results presented alongside exact solutions and absolute errors in $4 \mathrm{SBM}$ in the succeeding tables.

Table 1: Results Obtained via 4SBM and Exact Solution for Problem 1

\begin{tabular}{cccc}
\hline$x$ & $4 S B M$ & $E S$ & Error \\
\hline 0.05 & 1.000041656098423 & 1.000041656250930 & $1.525 \mathrm{E}-10$ \\
0.10 & 1.000333000034864 & 1.000333000119025 & $8.416 \mathrm{E}-11$ \\
0.15 & 1.001122470624527 & 1.001122470783193 & $1.587 \mathrm{E}-10$ \\
0.20 & 1.002656015266213 & 1.002656015226813 & $3.940 \mathrm{E}-11$ \\
0.25 & 1.005175853371282 & 1.005175853826862 & $4.556 \mathrm{E}-10$ \\
0.30 & 1.008919259675645 & 1.008919259923658 & $2.480 \mathrm{E}-10$ \\
0.35 & 1.014117357497459 & 1.014117357958868 & $4.614 \mathrm{E}-10$ \\
0.40 & 1.020993944784203 & 1.020993944707496 & $7.671 \mathrm{E}-11$ \\
0.45 & 1.029764337318100 & 1.029764338052525 & $7.344 \mathrm{E}-10$ \\
0.50 & 1.040634257260341 & 1.040634257659017 & $3.987 \mathrm{E}-10$ \\
0.55 & 1.053798741058314 & 1.053798741797931 & $7.397 \mathrm{E}-10$ \\
0.60 & 1.069441104559158 & 1.069441104449228 & $1.099 \mathrm{E}-10$ \\
0.65 & 1.087731935705026 & 1.087731936679154 & $9.741 \mathrm{E}-10$ \\
0.70 & 1.108828155610459 & 1.108828156138549 & $5.280 \mathrm{E}-10$ \\
0.75 & 1.132872107389567 & 1.132872108367968 & $9.784 \mathrm{E}-10$ \\
0.80 & 1.159990723559075 & 1.159990723421791 & $1.373 \mathrm{E}-10$ \\
0.85 & 1.190294729976340 & 1.190294731138058 & $1.162 \mathrm{E}-09$ \\
0.90 & 1.223877937554632 & 1.223877938183885 & $6.293 \mathrm{E}-10$ \\
0.95 & 1.260816568633841 & 1.260816569798685 & $1.165 \mathrm{E}-09$ \\
1.00 & 1.301168679097036 & 1.301168678939756 & $1.573 \mathrm{E}-10$ \\
\hline
\end{tabular}

Table 2: Results Obtained via 4SBM and Exact Solution for Problem 2

\begin{tabular}{cccc}
\hline$x$ & $4 S B M$ & $E S$ & Error \\
\hline 0.05 & 0.537804876867552 & 0.537804878048781 & $1.181 \mathrm{E}-09$ \\
0.10 & 0.576190475537360 & 0.576190476190476 & $6.531 \mathrm{E}-10$ \\
0.15 & 0.615116277982668 & 0.615116279069767 & $1.087 \mathrm{E}-09$ \\
0.20 & 0.654545454626120 & 0.654545454545455 & $8.067 \mathrm{E}-11$ \\
0.25 & 0.694444443897402 & 0.694444444444444 & $5.470 \mathrm{E}-10$ \\
0.30 & 0.734782608422214 & 0.734782608695652 & $2.734 \mathrm{E}-10$ \\
0.35 & 0.775531914385746 & 0.775531914893617 & $5.079 \mathrm{E}-10$ \\
0.40 & 0.816666666773689 & 0.816666666666667 & $1.070 \mathrm{E}-10$ \\
0.45 & 0.858163265060936 & 0.858163265306122 & $2.452 \mathrm{E}-10$ \\
0.50 & 0.899999999904091 & 0.900000000000000 & $9.591 \mathrm{E}-11$ \\
0.55 & 0.942156862515474 & 0.942156862745098 & $2.296 \mathrm{E}-10$ \\
0.60 & 0.984615384726837 & 0.984615384615385 & $1.115 \mathrm{E}-10$ \\
\hline
\end{tabular}

Tropical Journal of Science and Technology, Volume 1 Number 2, 2020 
Isah I. O., Salawu, A. S., Olayemi, K. S. and Enesi. L. O.: An Efficient 4-Step Block Method for Solution ff First Order Initial Value Problems via Shifted Chebyshev Polynomial

\begin{tabular}{llll}
\hline 0.65 & 1.027358490470479 & 1.027358490566038 & $9.556 \mathrm{E}-11$ \\
0.70 & 1.070370370359789 & 1.070370370370370 & $1.058 \mathrm{E}-11$ \\
0.75 & 1.113636363545846 & 1.113636363636364 & $9.052 \mathrm{E}-11$ \\
0.80 & 1.157142857249961 & 1.157142857142857 & $1.071 \mathrm{E}-10$ \\
0.85 & 1.200877192962900 & 1.200877192982456 & $1.956 \mathrm{E}-11$ \\
0.90 & 1.244827586237433 & 1.244827586206897 & $3.054 \mathrm{E}-11$ \\
0.95 & 1.288983050828196 & 1.288983050847458 & $1.926 \mathrm{E}-11$ \\
1.00 & 1.333333333432874 & 1.333333333333333 & $9.954 \mathrm{E}-11$ \\
\hline
\end{tabular}

Table 3: Results Obtained via 4SBM and Exact Solution for Problem 3

\begin{tabular}{cccc}
\hline$x$ & $4 S B M$ & $E S$ & Error \\
\hline 0.05 & 0.947368868660920 & 0.947368421052632 & 4.476 E-07 \\
0.10 & 0.888889196924966 & 0.888888888888889 & 3.080 E-07 \\
0.15 & 0.823529956981598 & 0.823529411764706 & 5.452 E-07 \\
0.20 & 0.750000100472588 & 0.750000000000000 & 1.005 E-07 \\
0.25 & 0.666669415808271 & 0.666666666666667 & 2.749 E-06 \\
0.30 & 0.571430589912683 & 0.571428571428571 & 2.018 E-06 \\
0.35 & 0.461542012435517 & 0.461538461538462 & 3.551 E-06 \\
0.40 & 0.333334332177455 & 0.333333333333333 & 9.988 E-07 \\
\hline
\end{tabular}

Table 4: Results Obtained via 4SBM and Exact Solution for Problem 4

\begin{tabular}{cccc}
\hline$x$ & $4 S B M$ & $E S$ & Error \\
\hline 0.05 & 0.415973405593861 & 0.417858610442121 & $1.885 \mathrm{E}-03$ \\
0.10 & 0.235280102523366 & 0.235168699883441 & $1.114 \mathrm{E}-04$ \\
0.15 & 0.198429486948619 & 0.199225200841463 & $7.957 \mathrm{E}-04$ \\
0.20 & 0.218842241432046 & 0.216984969683795 & $1.857 \mathrm{E}-03$ \\
0.25 & 0.254787128316857 & 0.254141906253608 & $6.452 \mathrm{E}-04$ \\
0.30 & 0.298252560545128 & 0.297998958838006 & $2.536 \mathrm{E}-04$ \\
0.35 & 0.343886105695109 & 0.343809689421006 & $7.642 \mathrm{E}-05$ \\
0.40 & 0.389825288561599 & 0.389753804936553 & $7.148 \mathrm{E}-05$ \\
0.45 & 0.435114474159927 & 0.435088943915317 & $2.553 \mathrm{E}-05$ \\
0.50 & 0.479480658115133 & 0.479470938533965 & $9.720 \mathrm{E}-06$ \\
0.55 & 0.942156862515474 & 0.522703930631449 & $3.235 \mathrm{E}-06$ \\
0.60 & 0.564650682571834 & 0.564648617607389 & $2.064 \mathrm{E}-06$ \\
0.65 & 0.605189410336500 & 0.605188666065447 & $7.443 \mathrm{E}-07$ \\
0.70 & 0.644218799129693 & 0.644218518766410 & $2.804 \mathrm{E}-07$ \\
0.75 & 0.681639162254277 & 0.681639065925655 & $9.633 \mathrm{E}-08$ \\
0.80 & 0.717356256350970 & 0.717356203434697 & $5.292 \mathrm{E}-08$ \\
0.85 & 0.751280465803523 & 0.751280446539670 & $1.926 \mathrm{E}-08$ \\
0.90 & 0.783326932020669 & 0.783326924857463 & $7.163 \mathrm{E}-09$ \\
0.95 & 0.813415512958577 & 0.813415510392170 & $2.566 \mathrm{E}-09$ \\
1.00 & 0.841470987962095 & 0.841470986869050 & $1.093 \mathrm{E}-09$ \\
\hline
\end{tabular}

Tropical Journal of Science and Technology, Volume 1 Number 2, 2020 
Isah I. O., Salawu, A. S., Olayemi, K. S. and Enesi. L. O.: An Efficient 4-Step Block Method for Solution ff First Order Initial Value Problems via Shifted Chebyshev Polynomial

Also, the maximum errors via applying 4SBM, SCNM and SDIBBDF to solve Problems 1 to 4 in their respective integration interval with varied values of step length given as: $h=0.5,0.25$, $0.125,0.0625$ and 0.03125 are obtained. The results are given in the next three tables:

Table 5: Maximum Error in 4SBM, SCNM and SDIBBDF for Problem 1

\begin{tabular}{cccc}
\hline$h$ & $\begin{array}{c}\text { Maximum } \\
\text { 4SBM }\end{array}$ & $\begin{array}{c}\text { Error } \\
\text { SCNM }\end{array}$ & SDIBBDF \\
\hline 0.05 & $1.1648432348 \mathrm{E}-09$ & $9.1679143038 \mathrm{E}-04$ & $1.2872612859 \mathrm{E}-02$ \\
0.025 & $1.7545844683 \mathrm{E}-11$ & $2.3039010417 \mathrm{E}-04$ & $6.7243621653 \mathrm{E}-03$ \\
0.0125 & $2.9739429002 \mathrm{E}-13$ & $6.5412117264 \mathrm{E}-07$ & $3.4341600817 \mathrm{E}-03$ \\
0.00625 & $4.7368321743 \mathrm{E}-15$ & $1.6251493433 \mathrm{E}-07$ & $1.7350726080 \mathrm{E}-03$ \\
0.003125 & $7.3317461306 \mathrm{E}-17$ & $3.6162173629 \mathrm{E}-08$ & $8.7203430942 \mathrm{E}-04$ \\
\hline
\end{tabular}

Table 6: Maximum Error in 4SBM, SCNM and SDIBBDF for Problem 2

\begin{tabular}{cccc}
\hline$h$ & $\begin{array}{c}\text { Maximum } \\
\text { SSBM }\end{array}$ & $\begin{array}{c}\text { Error } \\
\text { SCNM }\end{array}$ & SDIBBDF \\
\hline 0.05 & $1.08709943881 \mathrm{E}-09$ & $1.08543181681 \mathrm{E}-05$ & $1.6071672413 \mathrm{E}-03$ \\
0.025 & $2.17329064171 \mathrm{E}-11$ & $2.64907317363 \mathrm{E}-06$ & $6.1855030453 \mathrm{E}-04$ \\
0.0125 & $3.69327425795 \mathrm{E}-13$ & $6.54121172638 \mathrm{E}-07$ & $3.8188162246 \mathrm{E}-04$ \\
0.00625 & $6.02183095715 \mathrm{E}-15$ & $1.62520328014 \mathrm{E}-07$ & $1.8932254244 \mathrm{E}-04$ \\
0.003125 & $9.61310579295 \mathrm{E}-17$ & $4.05043625252 \mathrm{E}-08$ & $9.4258783854 \mathrm{E}-05$ \\
\hline
\end{tabular}

Table 7: Maximum Error in 4SBM, SCNM and SDIBBDF for Problem 3

\begin{tabular}{cccc}
\hline$h$ & $\begin{array}{c}\text { Maximum } \\
\text { 4SBM }\end{array}$ & $\begin{array}{c}\text { Error } \\
\text { SCNM }\end{array}$ & SDIBBDF \\
\hline 0.05 & $3.5508970546 \mathrm{E}-06$ & $5.0224441532 \mathrm{E}-03$ & $3.6129445482 \mathrm{E}-02$ \\
0.025 & $8.3887224623 \mathrm{E}-08$ & $1.3518201515 \mathrm{E}-03$ & $2.0630450070 \mathrm{E}-02$ \\
0.0125 & $1.6471472949 \mathrm{E}-09$ & $3.5047481168 \mathrm{E}-04$ & $1.1036160711 \mathrm{E}-02$ \\
0.00625 & $2.1872547934 \mathrm{E}-11$ & $8.9209176545 \mathrm{E}-05$ & $5.7105713993 \mathrm{E}-03$ \\
0.003125 & $3.1582112998 \mathrm{E}-13$ & $2.2502483560 \mathrm{E}-05$ & $2.9051182479 \mathrm{E}-03$ \\
\hline
\end{tabular}

Table 8: Maximum Error in 4SBM, SCNM and SDIBBDF for Problem 4

\begin{tabular}{cccc}
\hline$h$ & $\begin{array}{c}\text { Maximum } \\
\text { 4SBM }\end{array}$ & $\begin{array}{c}\text { Error } \\
\text { SCNM }\end{array}$ & SDIBBDF \\
\hline 0.05 & $3.5508970546 \mathrm{E}-06$ & $6.5870995837 \mathrm{E}-01$ & $6.6243451748 \mathrm{E}-04$ \\
0.025 & $8.3887224623 \mathrm{E}-08$ & $6.5857260320 \mathrm{E}-01$ & $3.3472344598 \mathrm{E}-04$ \\
0.0125 & $1.6471472949 \mathrm{E}-09$ & $6.5853971240 \mathrm{E}-01$ & $1.6829289554 \mathrm{E}-04$ \\
0.00625 & $2.1872547934 \mathrm{E}-11$ & $6.5853166363 \mathrm{E}-01$ & $8.4384411578 \mathrm{E}-05$ \\
0.003125 & $3.1582112998 \mathrm{E}-13$ & $6.5787969735 \mathrm{E}-01$ & $4.2252348871 \mathrm{E}-05$ \\
\hline
\end{tabular}

The maximum errors presented in tables 5 to 8 are visualized in figures 5 to 8 respectively to further illustrate the superiority of $4 \mathrm{SBM}$ over the existing methods under consideration. 
Isah I. O., Salawu, A. S., Olayemi, K. S. and Enesi. L. O.: An Efficient 4-Step Block Method for Solution ff First Order Initial Value Problems via Shifted Chebyshev Polynomial

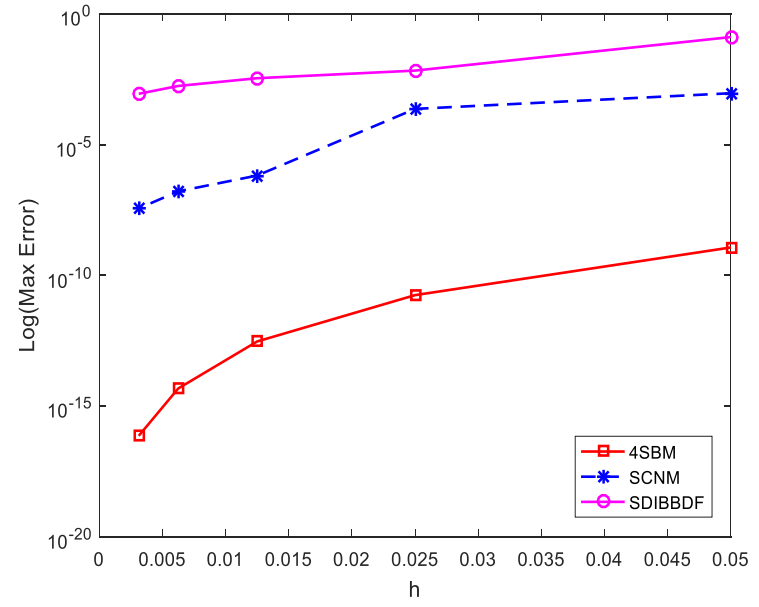

Fig 5: Comparison of Errors for Problem 1

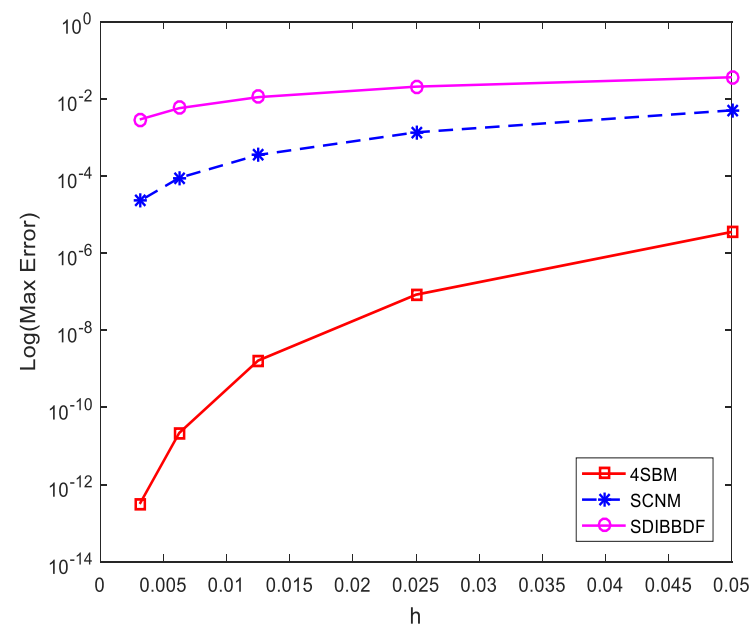

Fig 7: Comparison of Errors for Problem 3

\section{Discussion}

In this paper, we developed a 4 step block linear multistep (4SBM) method for solving IVPs in ODEs. The scheme was derived via Chebyshev Polynomial as the interpolating function. The properties of the 4SBM were extensively discussed. It is clear from the analysis of the properties of the derived 4SBM that the method is consistent, stable, and convergent with the discrete schemes in the method having non-uniform order of accuracy, the minimum of which was five. Four numerical examples were solved successfully as test problems in order to evaluate the performance of 4SBM in terms of accuracy and stability. Tables 1-4 shows

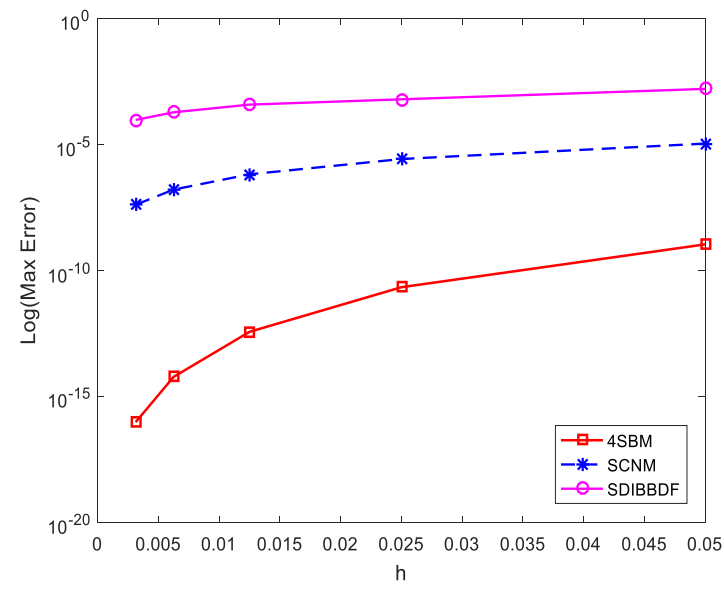

Fig 6: Comparison of Errors for Problem 2

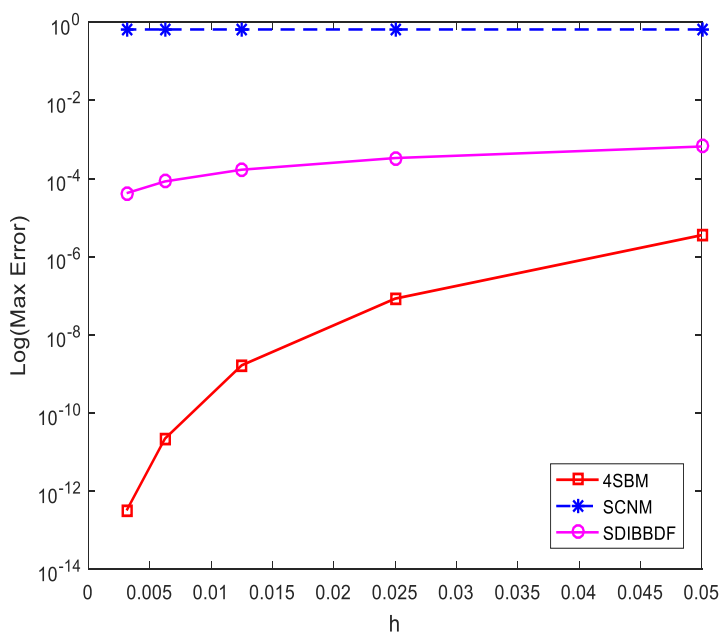

Fig 8: Comparison of Errors for Problem 4

the results obtained when solving the four test problems in their respective integration intervals presented alongside exact solutions. It can be seen that the 4SBM agreed with the exact solutions to a quite appreciable extent. Furthermore, a comparative study of 4SBM, SOCNM and SDIBBDF was also presented. By varying the step length, the maximum errors obtainable within the associated integration interval for each problem was computed.

\section{Conclusion}

The results generated from the comparative study of the 4SBM, SOCNM and SDIBBDF are given in tables 5 to 8 and displayed 
Isah I. O., Salawu, A. S., Olayemi, K. S. and Enesi. L. O.: An Efficient 4-Step Block Method for Solution ff First Order Initial Value Problems via Shifted Chebyshev Polynomial

graphically in figures 5 through 8 . It can be observed that the derived $4 \mathrm{SBM}$ competes favourably with the other methods under review. While it is quite obvious from the numerical results in tables 5 to 8 that 4 SBM is more accurate than its equals, it is equally visible from the maximum error curves in Figures 5, 6, 7 and 8 that there is an impressive deterioration in the errors generated via 4SBM as the step size decreases, a confirmation of the suitability of the derived method to the model problems. Consequently, we conclude that the derived $4 \mathrm{SBM}$ is accurate, stable and hence a good self-starting numerical solver for IVPs of different characteristics in ODEs.

\section{References}

Aboiyar T., Luga T., \& Iyorter B. V., 2015. "Derivation of continuous linear multistep methods using hermite polynomials as basic functions," American Journal of Applied Mathematics and Statistics, 3:220225.

Adeniyi R. B. \& Alabi M. O., 2007. "Continuous formulation of a class accurate implicit linear multistep methods with Chebyshev basis function in a collocation technique," Journal of Mathematical Association of Nigeria (ABACUS) 34: 58-77.

Adeniyi R. B., Adeyefa E. O. and Alabi M. O., 2006. "A continuous formulation of some classical initial value solvers by non-perturbed multistep collocation approach using Chebyshev Polynomial as basis function," Journal of the Nigerian Association of Mathematical Physics 10:261-274,

Adeyeye O. and Kayode S. J., 2013. "Twostep two-point hybrid methods for general second order differential equations," African Journal of
Mathematics and Computer Science Research, 6:191-196, Available at: https://doi.org/10.5897/AJMCSR201 3.0502 .

Aksah J. S., Ibrahim Z. B. and Zawawi I. S. M., 2019. "Stability analysis of singly diagonally Implicit Block Backward Differentiation Formulas for stiff ordinary differential equations", Research gate Publication, http://doi.org/10.3390/math7020211. Awoyemi D. O., Kayode S. J. and Adoghe L. O., 2014. "A five step P-stable method for the numerical integration of third order ordinary differential equations", American Journal of Computational Mathematics 4:119 126.

Ayinde S. O. and Ibijola E. A., 2015. "A new numerical method for solving first order differential equations", American Journal of Applied Mathematics and Statistics. 3(4): 156-160.

Fadugba S. E and Falodun B. O., 2017. "Development of a new one-step scheme for the solution of initial value problem (IVP) in ordinary differential equations", International Journal of Theoretical and Applied Mathematics 3:58.

Fadugba S. E. and Idowu J. O., 2019. "Analysis of the properties of a third order convergence numerical method derived via transcendental function of exponential form", International Journal of Applied Mathematics and Theoretical Physics 5: 97-110.

Fadugba S. E. and Okunlola J. T., 2017. "Performance measure of a new onestep numerical technique via interpolating function for the solution of initial value problem of first order differential equation", World Scientific News 90: 77. 
Isah I. O., Salawu, A. S., Olayemi, K. S. and Enesi. L. O.: An Efficient 4-Step Block Method for Solution ff First Order Initial Value Problems via Shifted Chebyshev Polynomial

Fadugba S. E., Ogunyebia S. N. and Falodun B. O., 2020. "An Examination of a Second order numerical method for solving initial value problems. Journal of the Nigerian Society of Physical Sciences, J. Nig. Soc. Phys. Sci. 2: 120-127.

Fatunla S.O., 1991. "Block methods for second order ODEs", International Journal of Computer Mathematics, 41, pp 55-63.

Henrici P., 1962. Discrete variable methods for ODEs. New York: John Wiley, 1962.

Lambert J. D., 1973. Computational Methods in ODEs. John Wiley \& Sons, New York.

Lambert J. D., 1991. Numerical methods for ordinary differential systems: the initial value problem, John Wiley \& Sons, Inc., New York.

Mohammed U. and Yahaya Y. A., 2010. "Fully implicit four-point block backward difference formula for solving first order initial value problems", Leonardo Journal of Sciences, 16 (1):21-30.

Odekunle M. R., Adesanya A. O. and Sunday J., 2012. "4-Point Block Method for Direct Integration of First-Order Ordinary Differential Equations", Internal Journal of Engineering Research and Applications (IJERA), 2(5):11821187.

Ogunrinde R. B., Fadugba S. E. and Okunlola J. T., 2012. "On some numerical methods for solving initial value problems in ordinary differential equations," IOSR Journal of Mathematics 1: 25-33, Available at: http;//dx.doi. org/10.9790/5728013253.

Olanegan O. O., Ogunware B. G., Omole E. O., Oyinloye T. S., and Enoch B. T., 2016. "Some classes of continous hybrid linear mulstistep methods for the solution of first order ordinary differential equations," International Organization of Scientific Research, 11: 08 - 13, Available at: 10.9790/5728-11510813.

Onumanyi P., Awoyemi D. O, Jator S. N. and Sirisena U. W., 1994. "New linear multistep methods with continuous coefficients for first order initial value problems, Journal of Nigeria Mathematical Society, 13:27-51.

Suleiman M. B., Musa H., Ismail F., Senu N. \& Ibrahim Z. B., 2013. "An accurate block solver for stiff IVPs". ISRN, Applied Mathematics,

Sunday J., Adesanya A. O and Odekunle M. R., 2013. "Order six block integrator for the solution of first order ordinary differential equations", International Journal of Mathematics and Soft Computing, 3(1): 87-96.

Taiwo O. A., 2005. "Comparison of Collocation Methods for the Solution of Second Order Non-Linear Boundary Value Problem", International Journal of Computational Mathematics, Int J Comput Math, 82(11): 1389-1400.

Yahaya Y. A., 2007. "A note on the construction of numerov method through quadratic continuous polynomial for the general second order ODE", Journal of the Nigerian Association of Mathematical Physics, (11): 261 - 268. 